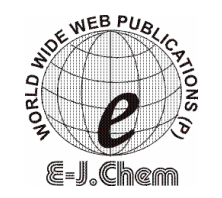

http://www.e-journals.net
ISSN: 0973-4945; CODEN ECJHAO

E-Journal of Chemistry

Vol. 5, No. 1, pp. 10-15, January 2008

\title{
Sensitive Spectrophotometric Methods for the Determination of Ascorbic Acid
}

\author{
H. D. REVANASIDDAPPA* and M. A. VEENA \\ Department of Chemistry, \\ University of Mysore, \\ Manasagangothri, Mysore-570 006, India. \\ hdrevanasiddappa@yahoo.com
}

Received 17 July 2007; Accepted 29 August 2007

\begin{abstract}
Two simple and sensitive spectrophotometric methods (A and $\mathrm{B}$ ) have been described for the determination of ascorbic acid. Method A is based on the oxidation of ascorbic acid (AA) by known excess of $\mathrm{Se}(\mathrm{IV})$ in hydrochloric acid medium and subsequent determination of unreacted $\mathrm{Se}(\mathrm{IV})$ by reacting it with iodide in the same acid medium to liberate iodine, which react with starch to form a stable blue coloured iodine-starch complex, which shows maximum absorbance at $590 \mathrm{~nm}$. Method B is based on the oxidation of ascorbic acid (AA) by known excess of $\mathrm{Cr}(\mathrm{VI})$ in sulphuric acid medium and the determination of unreacted $\mathrm{Cr}(\mathrm{VI})$ with diphenyl carbazide ( DPC) under the same acidic medium to produce a stable red-violet coloured species, which shows a maximum absorbance at $550 \mathrm{~nm}$. The reacted oxidants (in methods A and B) correspond to the AA content. The apparent molar absorptivity values are found to be $1.627 \times 10^{4}$ and $1.641 \times 10^{4} \mathrm{~L} \mathrm{~mol}^{-1} \mathrm{~cm}^{-1}$ for methods $\mathrm{A}$ and $\mathrm{B}$, respectively. The proposed methods are simple, sensitive and suitable for the routine analysis of AA in pharmaceutical formulations and in real samples.
\end{abstract}

Keywords: Ascorbic acid, Spectrophotometric method, Selenium(IV), Pharmaceuticals, Real samples.

\section{Introduction}

Ascorbic acid occurs in different concentrations in a variety of natural samples. It is added to several pharmaceutical products as an essential ingredient, a stabilizer for vitamin $\mathrm{B}$ complex, and as an anti-oxidant. Consequent upon its desirable effects, it is widely used in the treatment of certain diseases such as scurvy, anaemia, haemorrhagic disorders etc. 
It is considered essential for the development and regeneration of muscles, bones, teeth and skin. Also it has been identified as a radical scavenger in vivo. The therapeutic importance of AA has prompted many researchers to develop methods for its determination in real samples as well as in pharmaceuticals and these methods have been reviewed. ${ }^{1-3}$ The methods used for AA determination include titrimetric, spectrophotometric, fluorimetric, electrochemical, chromatographic, kinetic and chemiluminescens procedures. But due to their inherent limitations, these techniques (except titrimetric and spectrophotometric) are not commonly used for routine analysis. However, photometric methods are particularly attractive because of ease in accessibility and their quick applicability to routine analysis. Many spectrophotometric methods suggested for the determination of AA have been based on reduction of iron(III) to iron(II) with AA, followed by the complexation of reduced iron(II) with different reagents such as 1,10 - phenanthroline ${ }^{4}$, bipyridine ${ }^{5}$, and $p$-carboxyphenyl fluorone ${ }^{6}$. The reduction of $\mathrm{Cu}(\mathrm{II})$ to $\mathrm{Cu}(\mathrm{I})$ with $\mathrm{AA}$, the formed $\mathrm{Cu}(\mathrm{I})$ interacts with neocuproine reagent was the basis for its $[\mathrm{AA}]$ determination ${ }^{7}$. Some of these methods suffer from many disadvantages like use of heating step and $20 \mathrm{~min}$ for full colour development ${ }^{6}$, low sensitivity ${ }^{7}$ and poorer selectivity.

Few indirect spectrophotometric methods have been reported for analysis of AA utilizing iron(III) - thiocyanate complex ${ }^{8}$ and ferrozine ${ }^{9}$ Even these procedures are unsuitable for routine analysis, since the iron(III) - thiocyanate ${ }^{8}$ method required expensive experimental set-up [FIA]. To overcome these limitations in the existing methods, there is still a need for a sensitive and cost-effective method for the determination of ascorbic acid that can be employed for the routine analysis of it in pharmaceuticals as well as in real samples. The proposed methods utilized Se(IV) with starch-iodine and Cr (VI) with DPC for the determination of micro amounts of ascorbic acid in different samples.

\section{Experimental}

\section{Apparatus}

All absorbance measurements were made with ANALYTIC JENA AG model SPECORD50 and SYSTRONICS-166 spectrophotometers with $1 \mathrm{~cm}$ matched cells.

\section{Reagents}

All chemicals used were of analytical reagent grade. Selenium(IV) $\left[0.01 \mathrm{~mol} \mathrm{~L}^{-1}\right]$ : Prepared by dissolving $0.219 \mathrm{~g}$ of $\mathrm{Na}_{2} \mathrm{SeO}_{3}$ in $100 \mathrm{~mL}$ distilled water. A working standard solution was prepared by a suitable dilution of standard solution. Chromium(VI) $\left[0.01 \mathrm{~mol} \mathrm{~L}^{-1}\right]$ : Prepared by dissolving $0.2829 \mathrm{~g}$ of $\mathrm{K}_{2} \mathrm{Cr}_{2} \mathrm{O}_{7}$ in $100 \mathrm{~mL}$ distilled water. A working standard solution was prepared by a suitable dilution of standard solution. Aqueous solutions of potassium iodide [0.5\%], starch [1.0\%], 2.0 M hydrochloric acid and 1.0 M sulphuric acid were prepared. $0.25 \%$ DPC was prepared by dissolving $0.25 \mathrm{~g}$ of DPC in $100 \mathrm{~mL}$ of acetone.

\section{Standard solution}

Aqueous solution of ascorbic acid (AA) [Merck] was prepared daily by dissolving the required amount of the sample in doubly distilled water. Working solution was prepared as required by dilution.

\section{Standard procedures}

\section{Method A}

Different aliquots of the standard solution containing $0.5-8.0 \mu \mathrm{g} \mathrm{mL}^{-1}$ were transferred into a series of $10 \mathrm{~mL}$ standard flasks. Then, a volume of $0.2 \mathrm{~mL}$ of $50 \mu \mathrm{g} \mathrm{mL}{ }^{-1} \mathrm{Se}(\mathrm{IV})$ solution 
was added to each flask followed by acidification by $1.0 \mathrm{~mL}$ of $2.0 \mathrm{~mol} \mathrm{\textrm {L } ^ { - 1 }}$ hydrochloric acid. After $10 \mathrm{~min}, 1.5 \mathrm{~mL}$ of $0.5 \% \mathrm{KI}$ was added to each flask. After $2.0 \mathrm{~min}, 1.0 \mathrm{~mL}$ of $1.0 \%$ starch was added and the contents were diluted to the mark with distilled water and mixed well. The absorbance of the colored complex was measured at $580 \mathrm{~nm}$ against distilled water after $5.0 \mathrm{~min}$. Blank was prepared similarly omitting the AA and its absorbance was measured against distilled water. The decrease in absorbance corresponding to consumed $\mathrm{Se}(\mathrm{IV})$ and in turn, to AA concentration, obtained by subtracting the absorbance of AA solution from the corresponding blank. The calibration graph was drawn by plotting the difference in absorbance against the concentration of $\mathrm{AA}$, and the amount of AA was computed from the calibration curve.

\section{Method B}

Different aliquots of the standard solution containing $1.0-7.0 \mu \mathrm{g} \mathrm{mL}^{-1}$ were transferred into a series of $10 \mathrm{~mL}$ standard flasks. Then, a volume of $0.8 \mathrm{~mL}$ of $10 \mu \mathrm{g} \mathrm{mL} \mathrm{L}^{-1} \mathrm{Cr}(\mathrm{VI})$ solution was added to each flask followed by acidification by $1.0 \mathrm{~mL}$ of $1.0 \mathrm{~mol} \mathrm{~L}^{-1}$ sulphuric acid. After $10 \mathrm{~min}, 1.0 \mathrm{~mL}$ of $0.25 \%$ DPC was added to each flask and contents were diluted to the mark with distilled water and mixed well. The absorbance of the coloured species was measured at $550 \mathrm{~nm}$ against distilled water. Blank was prepared similarly by omitting the AA and its absorbance was measured against distilled water. The difference in absorbance values was used for constructing the calibration curve.

\section{Vitamin C tablets}

Twenty tablets of vitamin $\mathrm{C}$ were weighed and ground into a fine powder. An accurately weighed powder equivalent to $100 \mathrm{mg}$ of the active component was transferred into a $100 \mathrm{~mL}$ standard flask and dissolved in doubly distilled water and the mixture was shaken thoroughly for $20 \mathrm{~min}$. Then it was diluted to the mark with distilled water, mixed well and filtered using quantitative filter paper. An aliquot of this solution was diluted appropriately to obtain the working concentrations and analyzed as described under standard procedures

\section{Real samples, fruits and vegetables}

Fruits such as orange and lemon were squeezed and then they were filtered through a filter paper. The juice obtained was diluted quantitatively with distilled water for analysis. Vegetables such as tomato $(30 \mathrm{~g})$ and cucumber $(50 \mathrm{~g})$ were cut into small pieces and made into a paste in a mortar and then diluted to $100 \mathrm{~mL}$ with distilled water. The supernatant was filter through filter paper.

\section{Results and Discussion}

\section{Method A}

This method involves the oxidation of AA by Se(IV) in an acid medium. The unreacted $\mathrm{Se}(\mathrm{IV})$ reacts with iodide in the same acid medium to liberate iodine, which then reacts with starch to yield a blue coloured starch-iodine complex. This reaction system is the basis for the indirect spectrophotometric determination of AA. AA when added in increasing amounts, consume $\mathrm{Se}(\mathrm{IV})$ and decreases the concentration of $\mathrm{Se}(\mathrm{IV})$. The absorbance is found decrease linearly with increase in concentration of AA (Figure 1).

Hydrochloric acid was the medium of choice for oxidation of AA by Se(IV) as well as the latter's determination with iodine-starch reagent. A $1.0 \mathrm{~mL}$ of $2.0 \mathrm{~mol} \mathrm{~L}-1$ concentration of $\mathrm{HCl}$ was found to be optimum for the oxidation of AA within $10 \mathrm{~min}$, and hence the same 
concentration was employed for the determination of AA with Se(IV)- iodine-starch reagent. The volumes of $1.5 \mathrm{~mL}$ of $0.5 \% \mathrm{KI}$ and $1.0 \mathrm{~mL}$ of $1.0 \%$ starch solution in atal volume of $10 \mathrm{~mL}$ of reaction mixture were found to be suitable for the analysis.

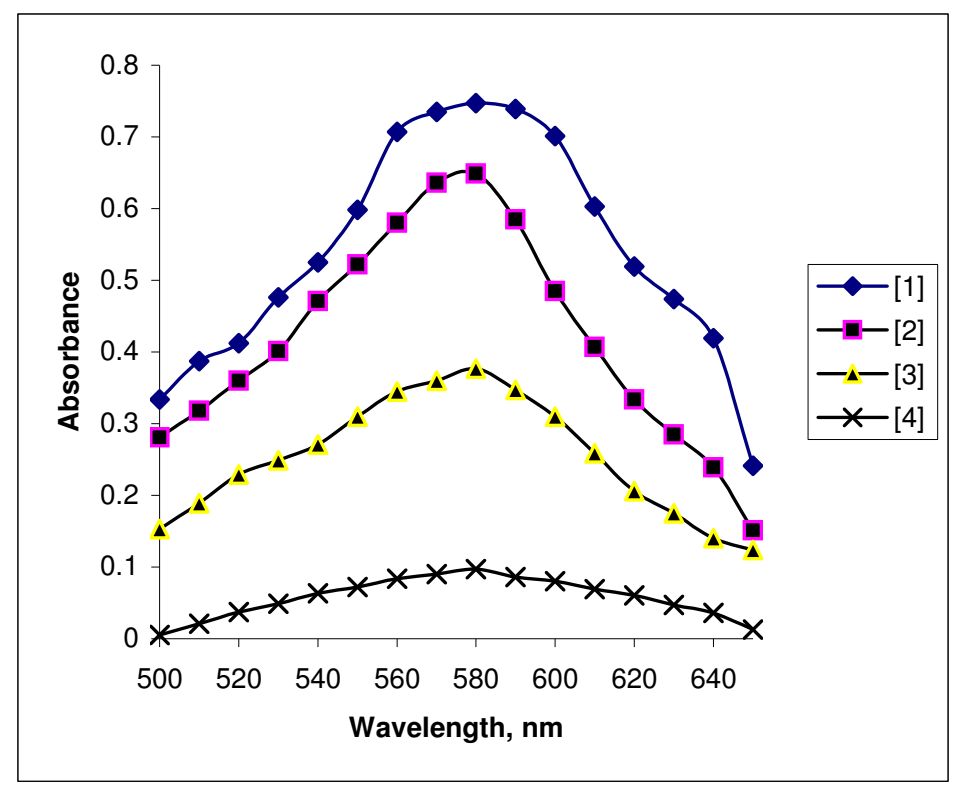

Figure 1. Absorption spectra of the Se(IV) - iodine -starch complex with ascorbic acid (1) Blank (without AA) (2) $1.0 \mu \mathrm{g} \mathrm{mL}^{-1}$ (3) $4.0 \mu \mathrm{g} \mathrm{mL} L^{-1}$ (4) $7.0 \mu \mathrm{g} \mathrm{mL}^{-1}$ measured against water.

\section{Method B}

In this method, known but excessive amount of $\mathrm{Cr}(\mathrm{VI})$ was used to oxidize AA in sulphuric acid medium, and the unreacted $\mathrm{Cr}(\mathrm{VI})$ was determined by reacting it with DPC in the same acidic medium. An increasing amount of AA was added, it consumes $\mathrm{Cr}(\mathrm{VI})$ and decreases the concentration of $\mathrm{Cr}(\mathrm{VI})$. The absorbance is found decrease linearly with increase in concentration of AA.

The various parameters involved in this method were optimized. Sulphuric acid was the medium of choice for the reaction between $\mathrm{Cr}(\mathrm{VI})$ and DPC and also for the oxidation of AA by $\mathrm{Cr}(\mathrm{VI})$. A volume of $1.0 \mathrm{~mL}$ each of the $1.0 \mathrm{~mol} \mathrm{~L}^{-1} \mathrm{H}_{2} \mathrm{SO}_{4}$ and $0.25 \%$ DPC were found to be suitable for the analysis. The formed reddish-violet product due to the reaction between the $\mathrm{Cr}(\mathrm{VI})$ and $\mathrm{DPC}$ and it was stable up to $90 \mathrm{~min}$.

\section{Analytical data}

The Beer's law limit, molar absorptivity, Sandell's sensitivity, correlation coefficient, detection and quantitation limits obtained by least square treatment of the results are given in Table 1.

\section{Applications to pharmaceuticals}

The proposed methods were applied to the quantitative determination of AA in vitamin C tablets and the results are presented in Table 2. A statistical analysis of the results by Students t-tests and $f$-tests showed no significant difference in accuracy and precision between the proposed and reference methods. In order to validate the possible analytical 
application of the methods, recovery experiments were performed on synthetic mixtures of AA with talc, dextrose, gelatin, glycine, thiamine, EDTA and other common excipients did not interfere with the assay

Table1. Optical characteristics and precision data

\begin{tabular}{lcc}
\hline \multicolumn{1}{c}{ Parameter } & A & B \\
\hline Beer's law limit, $\mu \mathrm{g} \mathrm{mL}^{-1}$ & $0.5-8.0$ & $1.0-7.0$ \\
Molar absorptivity, $\mathrm{L} \mathrm{mol}^{-1} \mathrm{~cm}^{-2}$ & $1.627 \times 10^{4}$ & $1.6416 \times 10^{4}$ \\
Sandell's sensitivity, $\mu \mathrm{g} \mathrm{cm}{ }^{-2}$ & 0.0108 & 0.0107 \\
Correlation coefficient (r) & 0.9999 & 0.9999 \\
Regression equation (Y*) & & \\
Slope (b) & 0.0924 & 0.09135 \\
Intercept (a) & $3.718 \times 10^{-4}$ & 0.00528 \\
Detection limit (DL) $\mu \mathrm{g} \mathrm{mL}^{-1}$ & 0.1570 & 0.2784 \\
Quantitation limit $(\mathrm{QL}), \mu \mathrm{g} \mathrm{mL}$ & 0.4757 & 0.8436 \\
\hline \multicolumn{2}{c}{$* \mathrm{Y}=\mathrm{a}+\mathrm{bx}$, where $\mathrm{x}$ is the concentration in $\mu \mathrm{g} \mathrm{mL}^{-1}}$.
\end{tabular}

Table 2. Results of assay of ascorbic acid in dosage forms

\begin{tabular}{|c|c|c|c|c|c|c|c|c|}
\hline 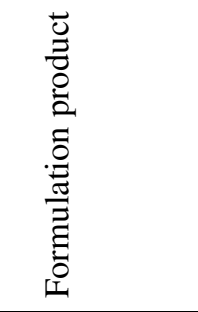 & $\begin{array}{l}\overrightarrow{0} \\
\stackrel{0}{0} \\
\stackrel{0}{\Sigma}\end{array}$ & 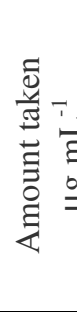 & 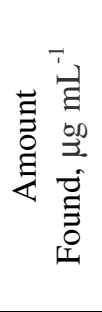 & $\begin{array}{c}\text { Method } \\
\% \operatorname{Rec} \pm \text { SD }\end{array}$ & 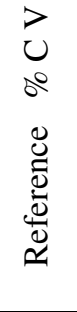 & $\begin{array}{c}\text { Method } \\
\text { \% Rec. } \pm \text { S D }\end{array}$ & $t$-value $\mathrm{e}^{\mathrm{b}}$ & $f$-value ${ }^{c}$ \\
\hline \multirow{6}{*}{$\begin{array}{l}\text { Citravite } \\
500 \mathrm{mg} / \mathrm{tab}\end{array}$} & \multirow{4}{*}{ A } & 1.0 & 0.99 & $99.70 \pm 0.65$ & 0.65 & $99.60 \pm 0.49$ & 0.79 & 1.76 \\
\hline & & 4.0 & 4.01 & $100.25 \pm 0.57$ & 0.14 & $100.20 \pm 0.86$ & 1.41 & 2.27 \\
\hline & & 7.0 & 7.09 & $101.28 \pm 0.82$ & 0.12 & $100.84 \pm 0.52$ & 1.04 & 2.49 \\
\hline & & 2.0 & 1.98 & $99.00 \pm 0.42$ & 0.21 & $100.40 \pm 0.51$ & 1.49 & 1.47 \\
\hline & \multirow[t]{3}{*}{ B } & 4.0 & 3.99 & $99.75 \pm 0.58$ & 0.15 & $101.20 \pm 0.36$ & 1.92 & 2.59 \\
\hline & & 6.0 & 6.10 & $101.67 \pm 0.27$ & 0.04 & $99.80 \pm 0.53$ & 1.57 & 3.85 \\
\hline \multirow{6}{*}{$\begin{array}{l}\text { Limcee } \\
500 \mathrm{mg} / \mathrm{tab}\end{array}$} & & 1.0 & 0.98 & $98.90 \pm 0.39$ & 0.39 & $101.7 \pm 0.48$ & 1.20 & 1.51 \\
\hline & \multirow[t]{2}{*}{ A } & 4.0 & 3.97 & $99.25 \pm 0.68$ & 0.17 & $99.68 \pm 0.87$ & 1.11 & 1.64 \\
\hline & & 7.0 & 6.99 & $99.98 \pm 0.82$ & 0.11 & $99.99 \pm 0.60$ & 0.97 & 1.87 \\
\hline & \multirow{3}{*}{ B } & 2.0 & 2.07 & $103.50 \pm 0.64$ & 0.31 & $99.98 \pm 0.55$ & 1.07 & 1.35 \\
\hline & & 4.0 & 3.99 & $99.95 \pm 0.75$ & 0.19 & $100.72 \pm 0.62$ & 1.13 & 1.46 \\
\hline & & 6.0 & 6.03 & $100.60 \pm 0.52$ & 0.09 & $101.00 \pm 0.77$ & 0.87 & 2.19 \\
\hline \multirow{6}{*}{$\begin{array}{l}\text { Celine } \\
500 \mathrm{mg} / \mathrm{tab}\end{array}$} & \multirow{3}{*}{ A } & 1.0 & 1.00 & $100.80 \pm 0.38$ & 0.37 & $100.32 \pm 0.27$ & 0.58 & 1.98 \\
\hline & & 4.0 & 3.97 & $99.33 \pm 0.72$ & 0.18 & $98.99 \pm 0.43$ & 0.71 & 2.8 \\
\hline & & 7.0 & 7.03 & $100.43 \pm 0.47$ & 0.06 & $99.96 \pm 0.84$ & 0.90 & 3.19 \\
\hline & \multirow{3}{*}{ B } & 2.0 & 1.99 & $99.95 \pm 0.63$ & 0.32 & $100.13 \pm 0.41$ & 0.85 & 2.36 \\
\hline & & 4.0 & 4.02 & $100.58 \pm 0.81$ & 0.20 & $99.99 \pm 0.50$ & 1.02 & 2.62 \\
\hline & & 6.0 & 5.98 & $99.67 \pm 0.77$ & 0.13 & $101.38 \pm 0.37$ & 0.49 & 4.33 \\
\hline
\end{tabular}

${ }^{\mathrm{a}}$ Average of five determinations, ${ }^{\mathrm{b}}$ Tabulated value $2.78,{ }^{\mathrm{c}}$ Tabulated value 6.39. 


\section{Recovery tests}

Recovery tests using the proposed methods were performed for three different samples and the test for each sample was carried out in triplicate and the recoveries of ascorbic acid added to cucumber, tomato, lemon and orange were about $99.61-102.33$ (Table 3). This indicates that the proposed methods give accurate results.

Table 3. Results of recovery test $\mathrm{mg} / 100 \mathrm{~g}$ and average of five determination

\begin{tabular}{ccccc}
\hline Sample & Method & AA (added) & AA (found) & $\%$, Rec \\
\hline \multirow{3}{*}{ Cucumber } & A & 00 & 2.57 & \\
& $\mathrm{~B}$ & 20 & 22.63 & 102.33 \\
Tomato & $\mathrm{A}$ & 00 & 22.56 & 99.61 \\
& $\mathrm{~B}$ & 20 & 14.82 & \\
Lemon & $\mathrm{A}$ & 20 & 35.00 & 101.21 \\
& $\mathrm{~B}$ & 20 & 34.90 & 100.53 \\
\multirow{5}{*}{ Orange } & $\mathrm{A}$ & 00 & 48.20 & \\
& $\mathrm{~B}$ & 20 & 69.17 & 102.01 \\
& & 20 & 79.78 & 101.2 \\
\hline
\end{tabular}

\section{Conclusions}

The proposed spectrophotometric methods for the determination of AA are simple, selective and offer the advantage of sensitivity without the need for extraction or heating. The assay methods do not involve any stringent reaction conditions, and non interference from associated substances in the dosage forms and real samples. The methods developed have been utilized to determine AA in real as well as in pharmaceutical samples.

\section{Acknowledgments}

One of the authors (M.A.V) is thankful to the University of Mysore, Mysore for providing the necessary facilities.

\section{References}

1. Arya S P, Mahajan P and Jain, Anal.Chim.Acta .2000, 417, 1.

2. Arya S P, Mahajan P and Jain, Anal. Sci., 1998, 14, 889

3. Ana-Maria Hossu, V. Magearu, , Roum.Biotech.Lett ., 2004, 9, 1497.

4. Anwar J, Farooqi M I, Nagra S A and Khan A M, J.Chem..Soc.Pak., 1990, 12, 75.

5. Fathi M R, Elahi R and Hashemi ,Chem.Anal( Warsaw). 2005, 50, 1069.

6. Fujita Y, Mori I, Yamaguchi M, Hoshino M, Shigemura Y and Shimano M, Anal. Sci., 2001, 17, 853.

7. Kubilay G, Kevser S, Esma T, Mustafa O and Resat A, Talanta, 2005, 65, 1226.

8. Noroozifar M, Khorasani-Motlagh M and Rahim A, Acta. Chim. Slov., 2004, 51, 717.

9. Molina-Diaz.A, Ortega-Carmona I and Pascual-Reguera M , Tlanta, 1998, 47, 531. 


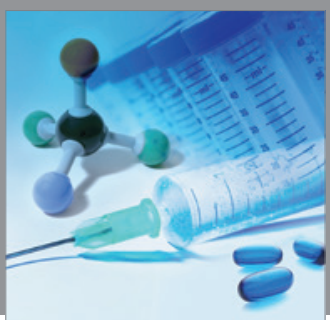

International Journal of

Medicinal Chemistry

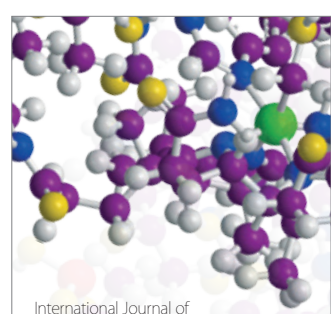

Carbohydrate Chemistry

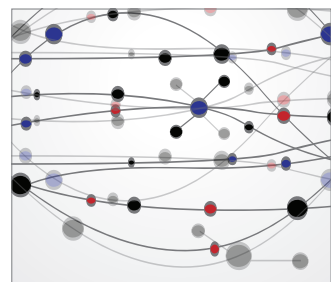

The Scientific World Journal
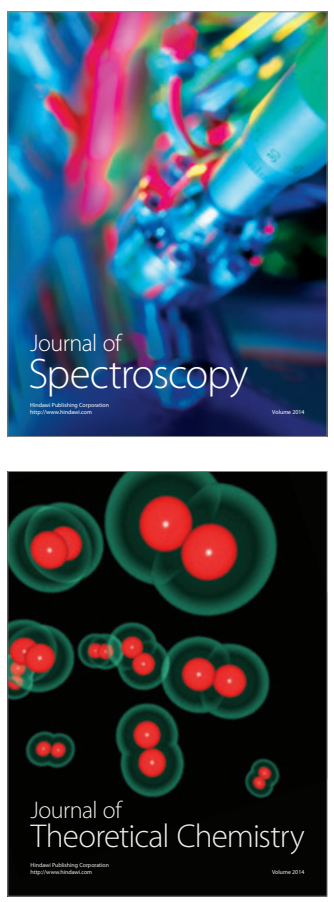
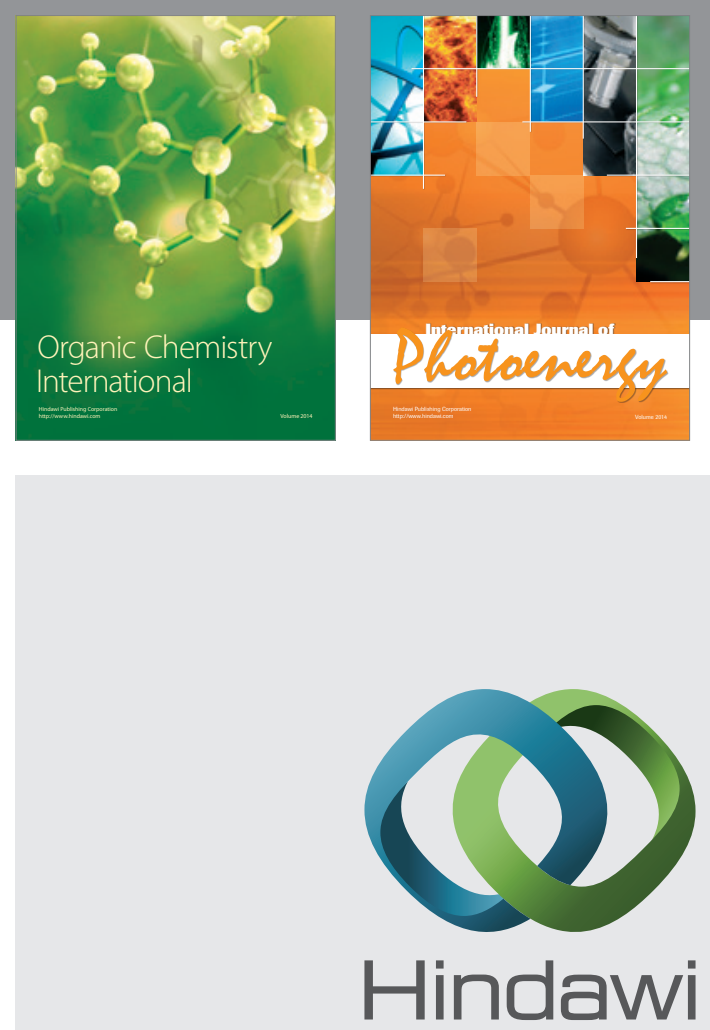

Submit your manuscripts at

http://www.hindawi.com
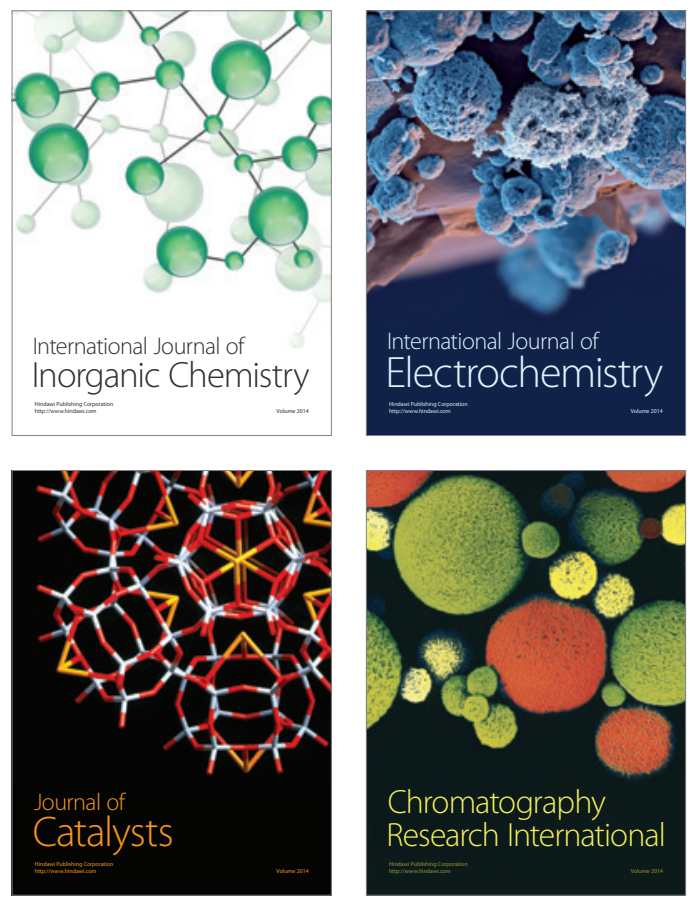
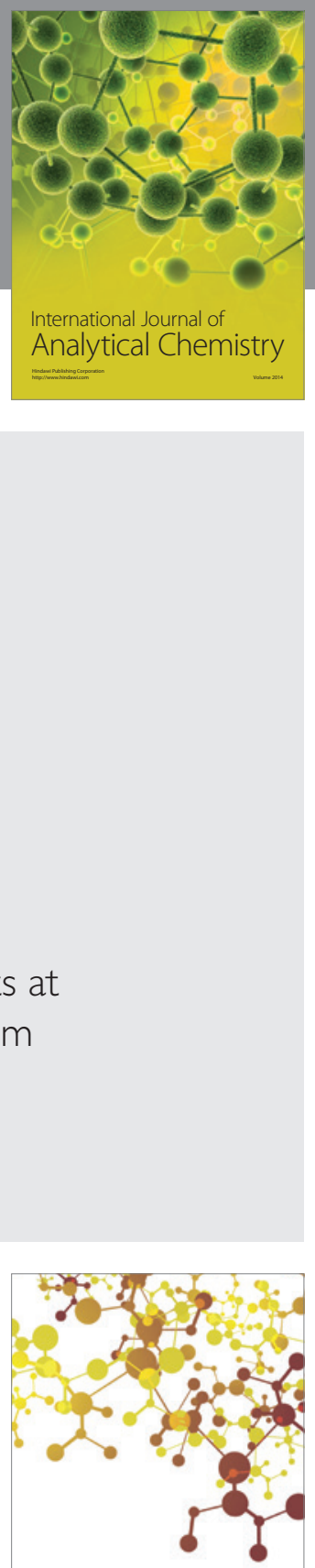

Journal of

Applied Chemistry
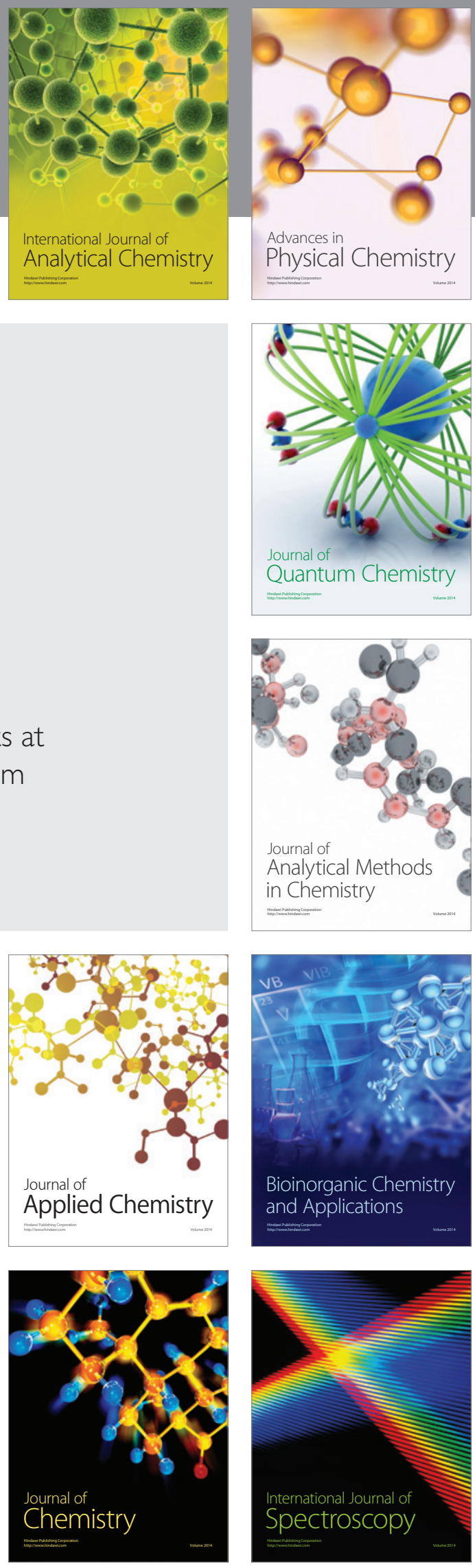